\title{
Discovery of Potential Anti-Ischemic Stroke Agents Through Inhibiting Sulfonylurea Receptor 1 (SUR1): A Pharmacophore-based Screening, Docking, and Molecular Dynamic Simulation
}

\author{
Melody Boroomandnezhad 1(i), Arash Amanlou ${ }^{2}(\mathbb{D})$, Sara Zareei ${ }^{1(\mathbb{D})}$, Nida Akhavan ${ }^{3}$, Massoud \\ Amanlou 1,2,*iD \\ 1 Department of Medicinal Chemistry, Faculty of Pharmacy, Tehran University of Medical Sciences, Tehran, Iran \\ 2 Experimental Medicine Research Center, Tehran University of Medical Sciences, Tehran, Iran \\ 3 Department of Medical Nanotechnology, Faculty of Advanced Sciences and Technology, Medical Sciences Branch, \\ Islamic Azad University (IAUMS), Tehran, Iran \\ * Correspondence: amanlou@tums.ac.ir (M.A.);
}

Scopus Author ID 6603321293

Received: 7.09.2021; Revised: 15.10.2021; Accepted: 20.10.2021; Published: 20.11.2021

\begin{abstract}
Stroke is the leading cause of disability and death worldwide. Inhibition of sulfonylurea 1 receptor (SUR1) using glibenclamide previously has been studied in CNS ischemic tissues and faster recovery from stroke injury in different animal models of stroke. Unfortunately, glibenclamide cannot enter the brain through an intact brain membrane (BBB) due to its ionization at physiological $\mathrm{pH}$. Therefore, it was hypothesized that compounds with structural properties similar to glibenclamide but with the ability to penetrate through $\mathrm{BBB}$ would be superior to glibenclamide in ischemic stroke. Docking energy and interactions of glibenclamide with SUR1 active site were assessed using AutoDock Vina. NCI databases search engines with limitations for penetration to CNS were used to find the best compounds with desired properties. Then two selected compounds were assessed with dynamic molecular studies. Two compounds called CID-415537 and CID-419074 with docking energies of $10.3 \mathrm{kcal} / \mathrm{mol}$ and $-11 \mathrm{kcal} / \mathrm{mol}$ were identified. CID-415537 was selected as the best compound due to its proper interactions with SUR1 amino acids and stability in molecular dynamic simulation. Based on this study, compound CID-415537 would be a good candidate for a SUR1 inhibitor in ischemic stroke. However, further in vivo investigations are required to confirm these findings.
\end{abstract}

Keywords: Sulfonylurea receptor 1; stroke; glibenclamide; molecular dynamic simulation; docking; virtual screening.

(C) 2021 by the authors. This article is an open-access article distributed under the terms and conditions of the Creative Commons Attribution (CC BY) license (https://creativecommons.org/licenses/by/4.0/).

\section{Introduction}

Stroke is a complex neurological disease, which leads to sudden paralysis, speech impairments, or vision loss caused by thromboembolic ischemic events, which second leading cause of death worldwide [1-3]. Cerebral ischemia is divided into focal ischemia and global ischemia. Global ischemia occurs during cardiac failure and interruption of blood flow to the brain. A reduced amount of blood supply causes a lack of oxygen and glucose, resulting in mitochondrial dysfunction, and reduction of ATP synthesis results in cerebral edema and hemorrhage [3-5]. Briefly, after the cerebral ischemia, morphological change in injured neuronal, glial, and endothelial cells is occurred due to cell swelling. Increased $\mathrm{Na}^{+}$and $\mathrm{Ca}^{2+}$ 
influx into cells by membrane depolarization and the lack of ATP are responsible for several harmful factors such as glutamate accumulation and reactive oxygen species (ROS) production due to cytotoxic cell swelling and acute injury that affects cerebral functions [6-10].

In search of receptors or channels involved in the ischemic stroke process, were reported that sulfonylurea 1 receptors increase after ischemic stroke [11,12]. Transcriptional upregulation transient receptor potential melastatin 4 (Trpm4), the nonselective monovalent cation channel, occurred in neural and vascular cells due to brain infarction, which associates with sulfonylurea receptor 1 (Sur1) to produce Sur1-Trpm4 channels which in cytotoxic edema, cell death, blood-brain barrier (BBB) breakdown, and extravasation edema have lifethreatening roles [10,13-17].

The SUR1-Trpm4 channel protects against the pathological increase in intracellular $\mathrm{Ca}^{+2}$ concentrations in normal conditions. However, extreme depletion in cellular ATP occurs during ischemic stroke deconditions due to reduced delivery of oxygen and glucose, two main sources for ATP production in the brain. Lower amounts of ATP constantly activate SUR1Trpm4 channels and cause constant cell depolarization via $\mathrm{Na}^{+}$influx, cytotoxic edema as a result of $\mathrm{Cl}^{-}$and water influx through depolarization, and finally, cell destruction [18-21]. Therefore, it seems that inhibition of SUR1-Trpm4 assembly may be an approach for modulating the outcomes of ischemic stroke [22-26].

It has been previously demonstrated that the SUR1-Trpm4 channel is plugged by first and second-generation sulfonylureas, tolbutamide $\left(\mathrm{EC}_{50}: 16.1 \mu \mathrm{M}\right)$, and glibenclamide $\left(\mathrm{EC}_{50}\right.$ : $48 \mathrm{nM}$ ) [23,27-30]. In the early 2000s, in seminal work by Simard et al., identifying a channel SUR1-TRPM4 in injured CNS cells was described, inhibited by sulfonylurea. Therefore the critical role of GLY was established in CNS injury, and it has enhanced events of increased intracranial pressure (ICP), brain swelling, disruption of the BBB, hippocampal injury, and amnesia [23,31-37]. These drugs block the channel by prolonging a long-closed state without affecting channel opening or conductivity $[14,29,38]$.

In a physiologically normal condition, the accumulation of glibenclamide and the other sulfonylurea drugs in the brain is not detectable [39,40]. The sulfonylurea drugs are passively transported into the brain and actively extruded out of the CNS cells. Extrusion of these compounds from BBB cells is active transport with an endothelial transporter similar to PGlycoprotein (P-gp) and maybe the organic anion transporters. Although lipophilicity is a critical factor of passive transport across an intact BBB, however, glibenclamide and tolbutamide as weak acids have two forms: an ionized form that is hydrophilic and impermeable and a non-ionized form that is lipophilic and permeable [41,42]. For glibenclamide, the ratio of ionized to non-ionized state is 100:1 at pH 7.3. It means it cannot transport into the brain at neutral $\mathrm{pH}$ because of poor lipid solubility and strong, tight junctions of intact BBB. Nevertheless, there are different conditions in ischemic strokes and similar dysfunctions because lactic acidosis can drive extracellular $\mathrm{pH}$ to values near 6.5, which leads to concentrated weak acidic compounds in cells $[43,44]$.

Therefore, the channels that contributed to the regulation of ionic homeostasis are considered promising as drug targets in ischemic stroke management. Considering the beneficial effect of glibenclamide on ischemic stroke and other types of neuroinflammation, it seems rational to reevaluate the interactions of glibenclamide with SUR1-Trpm4 to find other lead compounds through a pharmacophore-based virtual screening method without common side effects of sulfonylureas. 


\section{Materials and Methods}

\subsection{Methodology.}

The overall procedures of this study are illustrated in Figure 1.

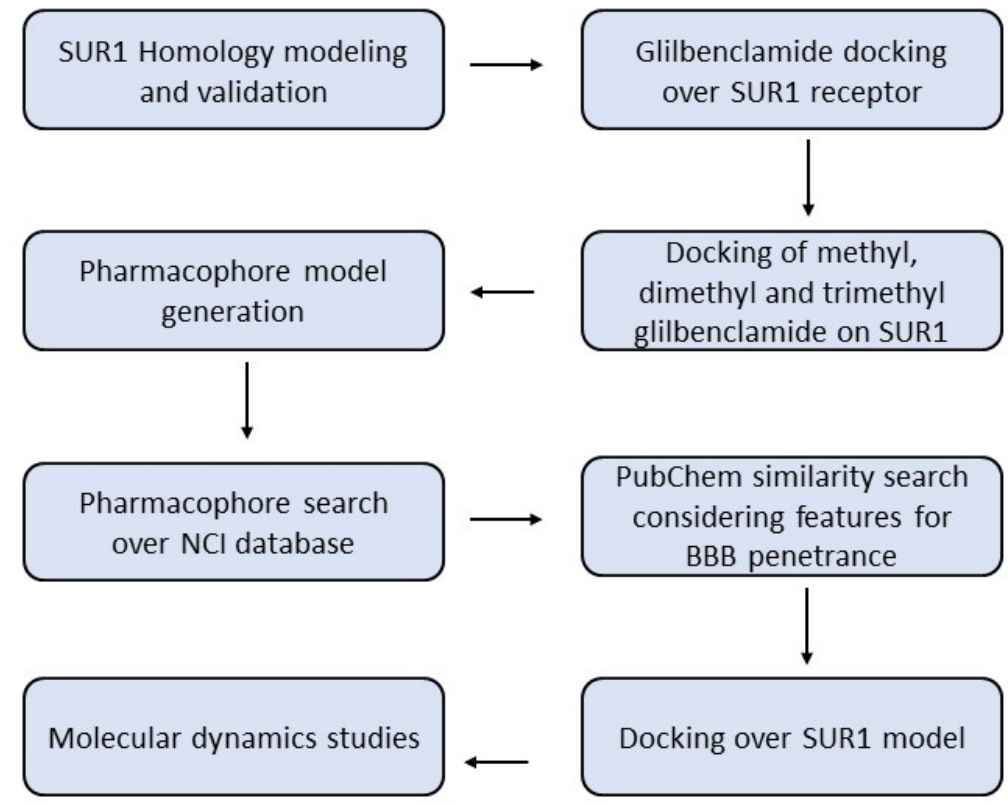

Figure 1. An overall view of finding new anti-stroke agents.

\subsection{SUR1 homology modeling.}

At the beginning of this study, the crystal structure of brain SUR1 was not available in Protein Data Bank (http://www.rcsb.org). The Swiss-model website (http://www.swissmodel.expasy.org) was used for homology modeling of SUR1 3D structure. Based on a survey showing structural similarities between the sulfonylurea drug-binding domain in P-glycoprotein (P-gp) and SUR1, the P-gp structure was used for the homology modeling procedure. For this purpose, the mouse P-gp crystal structure was obtained from Protein Data Bank with a PDB ID of 4KSB (www.rcsb.org).

Since it is demonstrated that comparative modeling is reliable when the sequence identity is above 30\% [45], SUR1 amino acid sequence (FASTA, accession code: Q09428 (ABCC8_HUMAN)) was extracted from the Protein Database (http://www.ncbi.nlm.nih.gov/protein) and compared to P-gp sequence retrieved from Protein Data Bank (https://www.rcsb.org). The P-gp sequence was uploaded as a template, and the Swiss-model server then built a model of SUR1 based on the minimum energy level and the most stable structure. The comparison was made by pairwise sequence alignment using the local alignment tool and EBLOSUM62 algorithm.

Validation of the SUR1 model was done with the SAVES server, a meta server in which six different programs are available for validating a protein structure. PROCHECK is one of the SAVES server modules (http://www.ebi.ac.uk/thornton-srv/software/PROCHECK/) stereochemically evaluate a protein structure and generate several data such as the Ramachandran plot. Then, a Ramachandran plot was generated for the homology modeled structure of SUR1, and the resolution was estimated, and allowable regions were detected. 


\subsection{Molecular docking simulations.}

AutoDockTools package (ADT, Ver. 1.5.6, The Scripps Research Institute, Florida, USA) was used to prepare all input files for docking simulations. To prepare protein files, polar hydrogens were added, non-polar hydrogens were merged, and the Kollman charges were assigned. All simulation parameters were set as default. Then, the protein input file was saved in PDBQT format. The chemical structure of glibenclamide and its derivatives were drawn using MarvinSketch (17.8.0) (ChemAxon) [46], explicit hydrogens were added and then saved in PDBQT format. Docking simulations were carried out by AutoDock Vina 1.1.2 program [47], with exhaustiveness set to 50. For both proteins, the search spaces were defined as $40 \times 40 \times 40 \AA$ ( $\mathrm{x}, \mathrm{y}$, and $\mathrm{z}$ coordinates: $-40.081,10.523,-18.087$ for SUR1 while $\mathrm{x}, \mathrm{y}$, and $\mathrm{z}$ coordinates: $40.686,5.067$, and 2.75 for P-gp (4KSB)) with a spacing of $0.375 \AA$ A. Finally, 3D representations of the ligand-protein interactions have been provided by PyMol [48] and $\operatorname{LigPlot}^{+}[49]$.

\subsection{Pharmacophore generation.}

LigandScout v3.01 software was used to identify essential residues at the glibenclamide binding cassette for the pharmacophore model's generation. This software allows to automatically check and set a map of interactions of macromolecules active site with ligands (glibenclamide) such as positive and negative ionizable area (PI and NI), H bond donor (HBD), $\mathrm{H}$ bond acceptor (HBA), aromatic ring (AR) and hydrophobic area (HA) [50].

\subsection{Virtual screening.}

After the pharmacophore generation, the PubChem search engine (http://pubchem.ncbi.nlm.nih.gov) was used for similarity search using glibenclamide as an input. For finding compounds with appropriate physicochemical properties that could cross through intact BBB, all filters were applied by default. All default filters were applied to finding the compounds with appropriate physicochemical properties that could cross through intact BBB [51]. The retrieved structures (481 compounds) were docked to the SUR1 binding cavity. Nine compounds with the lowest binding energy $(-7.7$ to $-10.6 \mathrm{kcal} / \mathrm{mol})$ and similar orientation to glibenclamide were considered for further investigations (Table 1).

Table 1. Nine compounds were chosen after pharmacophore-based NCI screening and docking simulations according to their docking binding free energy values and modes of interactions with SUR1.

\begin{tabular}{l|l|l|} 
Compound & Docking energy (kcal/mol) \\
\hline Compound A (CID-319435) & & \\
\hline Compound B (CID-215718) &
\end{tabular}




\begin{tabular}{|c|c|c|}
\hline Compound & Structure & Docking energy (kcal/mol) \\
\hline Compound E (CID-275971) & & -8.4 \\
\hline Compound F (CID-12488) & & -8.3 \\
\hline Compound G (CID-204262) & & -8.3 \\
\hline Compound H (CID-146771) & & -10.6 \\
\hline Compound I (CID-110300) & & -9.7 \\
\hline Glibenclamide & & -10.7 \\
\hline
\end{tabular}

Of these compounds, compound H (CID-146771) and compound I (CID-110300) had the most similarities to glibenclamide in docking properties such as binding free energy, interactions with key residues, and RMSD value. These two compounds had the highest binding affinity and lowest free energy of binding alongside nearly similar docking sites to glibenclamide compared to other compounds.

To enlarge the number of potential hits for SUR1-Trpm4 assembly, compounds $\mathrm{H}$ and I were used as a new input for the PubChem search engine. All compounds obtained from PubChem's second search were docked to the SUR1 binding cavity, and results were tabulated in Table 2.

Table 2. Fourteen compounds are chosen with BBB penetration and compounds $H$ and I as inquiry in the PubChem database according to their docking binding free energy values and modes of interactions with SUR1.

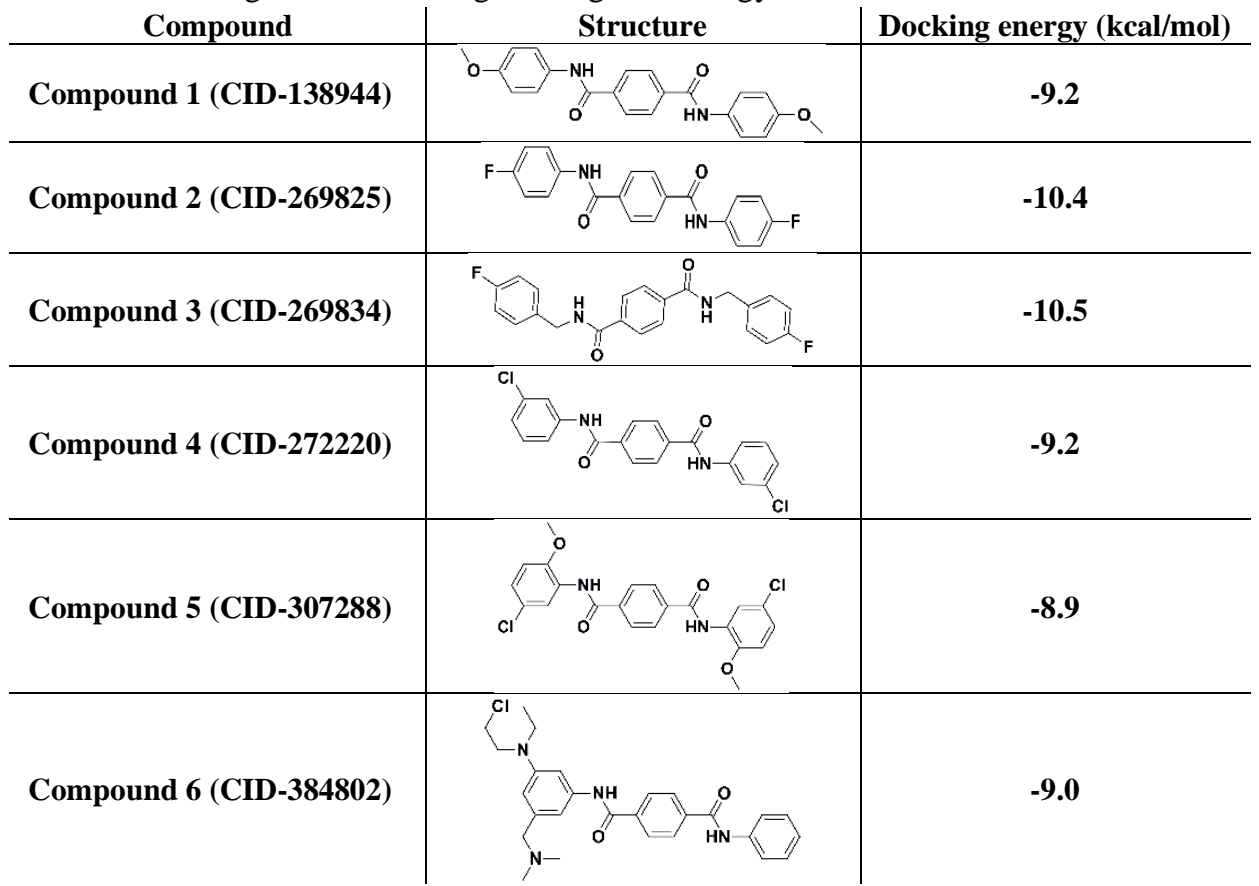




\begin{tabular}{|c|c|c|}
\hline Compound & Structure & Docking energy (kcal/mol) \\
\hline Compound 7 (CID-384804) & & -9.0 \\
\hline Compound 8 (CID-415376) & & -9.2 \\
\hline Compound 9 (CID-415537) & & -11.3 \\
\hline Compound 10 (CID-419072) & & -8.6 \\
\hline Compound 11 (CID-419073) & & -8.4 \\
\hline Compound 12 (CID-419074) & & -11.0 \\
\hline Compound 13 (CID-419167) & & -10.5 \\
\hline Compound 14 (CID-419168) & & -10.5 \\
\hline
\end{tabular}

\subsection{Molecular dynamic simulation.}

Molecular dynamic simulations were used to monitor probable interaction behavior of selected ligands (Compound 9, CID-415537 and Compound 12, CID-419074) and glibenclamide with SUR1 binding pocket. GROMACS package 5.0.1 was used, and the best docking posing of the selected compounds (9 and 12) and glibenclamide with SUR1 was chosen and used as the inputs of MD simulations [52]. The accurate protonation state of the residues was provided by the PROPKA server in $\mathrm{pH} 7.4$ (http://propka.org/) [53]. The topology files of SUR1 and the ligands were generated using the AMBER force field and the PRODRG server (http://prodrg1.dyndns.org), respectively [54]. Afterward, ligand-protein complexes were individually placed in a dodecahedron-shaped box, and the minimum distances between the protein surface and box walls were set to $1 \mathrm{~nm}$. This box was filled with water model molecules through GROMACS' solvation method. In the next step, complexes were energy minimized by the steepest descent algorithm with $1000 \mathrm{~kJ} / \mathrm{mol} / \mathrm{nm}$ tolerance. The system went through an NVT condition for 20 ps and NPT until a constant pressure of 1 bar was obtained. Finally, the MD simulations were carried out for a period of $60 \mathrm{~ns}$. Other MD parameters were assigned based on our previous study [55].

\subsection{ADMET analysis.}

The ADME properties and potential toxicity of the final hits were predicted using SwissADME (http://www.swissadme.ch/) and ProTox-II (ProTox-II - Prediction of TOXicity of chemicals (charite.de)) web server, respectively [56,57]. 


\section{Results and Discussion}

\subsection{SUR1 homology modeling.}

To generate the SUR1 3D structure, homology modeling was carried out using the Pgp structure as a template and SUR1 sequence (Figure 2). Comparative modeling can be reliable since pairwise alignment showed a 39.1\% similarity between P-gp and SUR1 sequences. After modeling the Swiss-model webserver, the modeled structure was stereochemically checked and validated by the PROCHECK server and the Ramachandran plot.
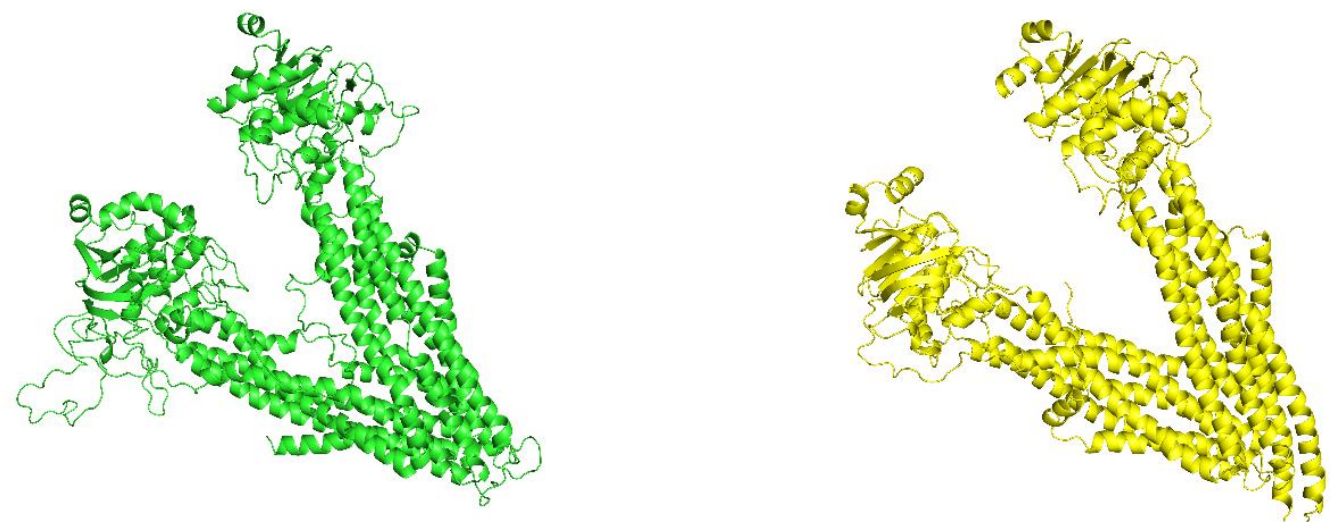

Figure 2. 3D representations of crystalized P-gp (PDB ID: 4KSB) (right) and SUR1 generated by homology modeling (left).

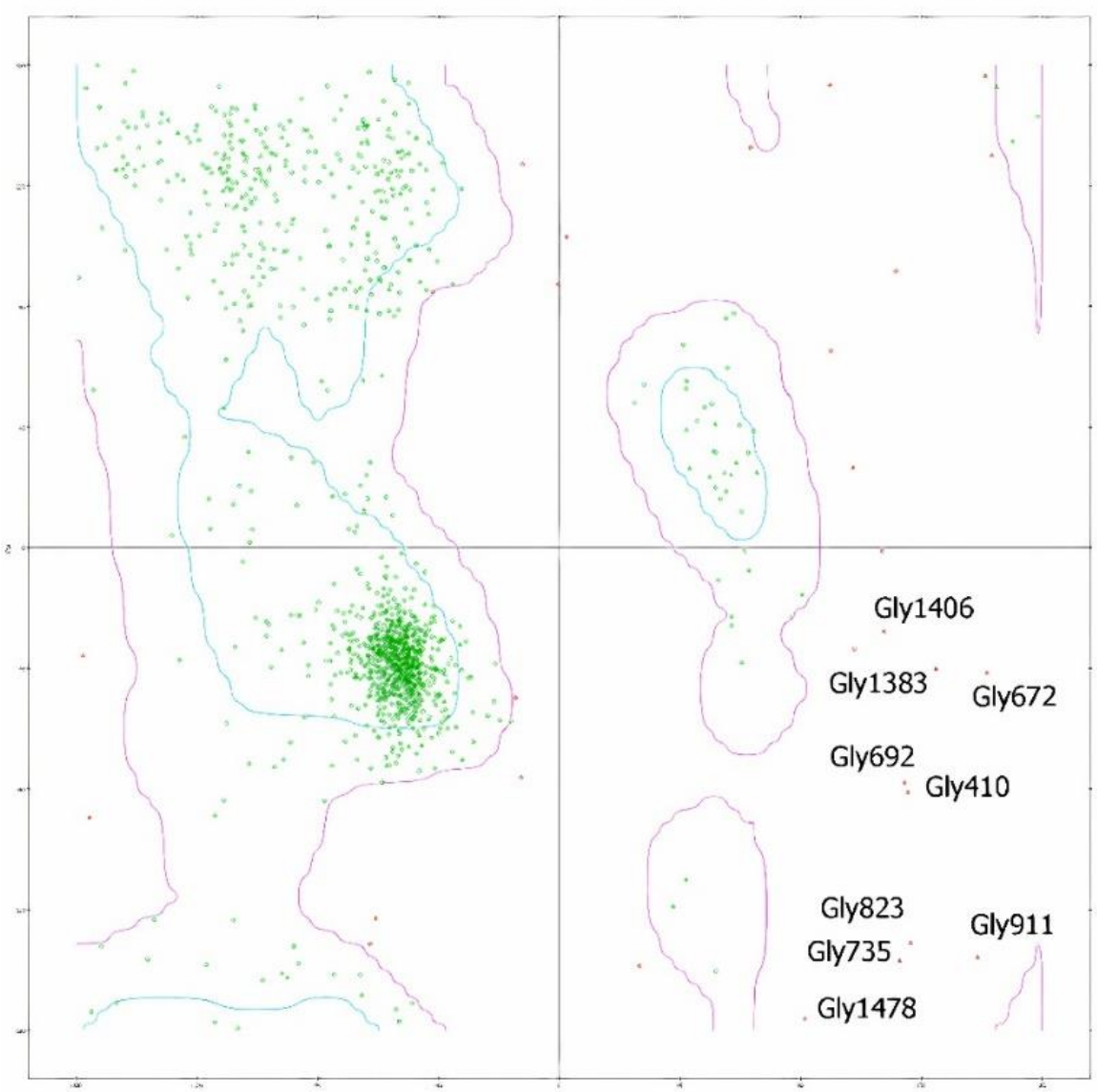

Figure 3. Ramachandran plot of SUR1 protein. Disallowed residues are specified in the plot. 
Besides, the estimated resolution was $1.5 \AA$, only about $0.9 \%$ of SUR1 residues were recognized as disallowing, including Gly 1406, Gly 1383, Gly 672, Gly 692, Gly 410, Gly 823, Gly 735, Gly 1478, and Gly 911 . None of them were in the glibenclamide binding region (Figure 3).

\subsection{Docking of glibenclamide on SURI and P-gp.}

Glibenclamide was docked to SUR1 and P-gp to validate the probable SUR1 binding region and the interactions involved. Glibenclamide is bound to both proteins in a similar binding region (Figure 4) with binding energy values of $-9.3 \mathrm{kcal} / \mathrm{mol}$ and $-10.7 \mathrm{kcal} / \mathrm{mol}$, suggesting that glibenclamide better affinity for SUR1 than P-gp. It was consistent with this theory that SUR1 ligands have more affinity for SUR1 than P-gp. Comparison of docking poses showed that glibenclamide was docked similarly in two receptors. As a confirmation for this method, the docking site was close to the amino acids mentioned above.
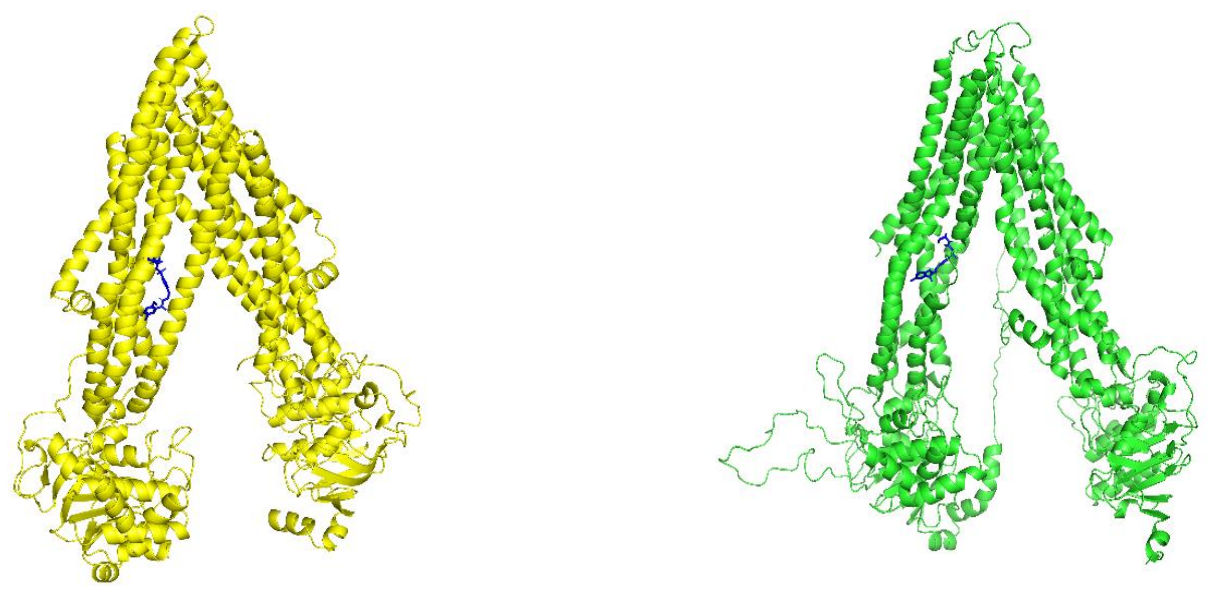

Figure 4. Overall representations of glibenclamide binding regions to P-gp (Left) and SUR1 (right). The glibenclamide molecule is presented as a blue stick.

A

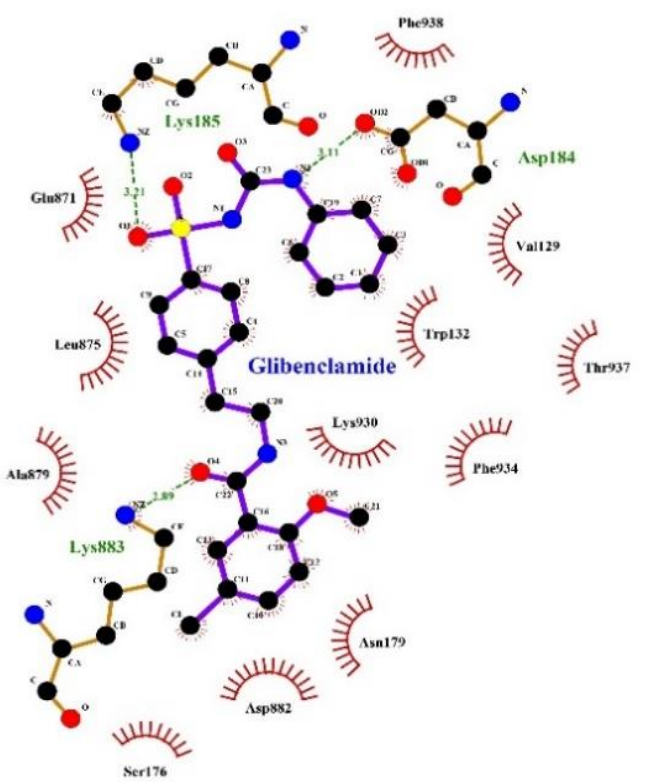

B

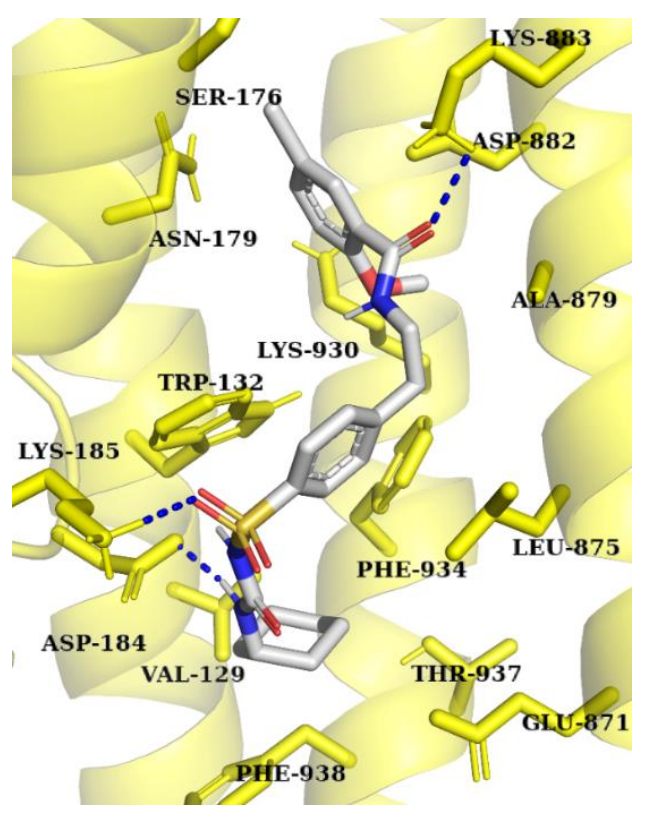

Figure 5. 2D and 3D illustrations of glibenclamide interactions with P-gp.

Dotted arrows represent hydrogen bonding. 
The residues involved in binding glibenclamide to P-gp are as follows: Asp 184, Lys 883, and Lys 185 make hydrogen bonds while Phe 938, Val 129, Trp 132, Thr 937, Lys 930, Phe 934, Asn 179, Asp 882, Ser 176, Ala 876, Leu 875, and Glu 871 contribute to hydrophobic interactions (Figure 5). However, the SUR1-glibenclamide complex is formed only by hydrophobic interactions made by Tyr 377, Phe 433, Val 1183, Ile 381, Ile 385, Met 429, Leu 1240, Trp 430, Leu 434, Tyr 1180, Arg 388, Ser 1237, Asn 1244, Phe 1181, Met 1251, and Glu 1248 residues (Figure 6).
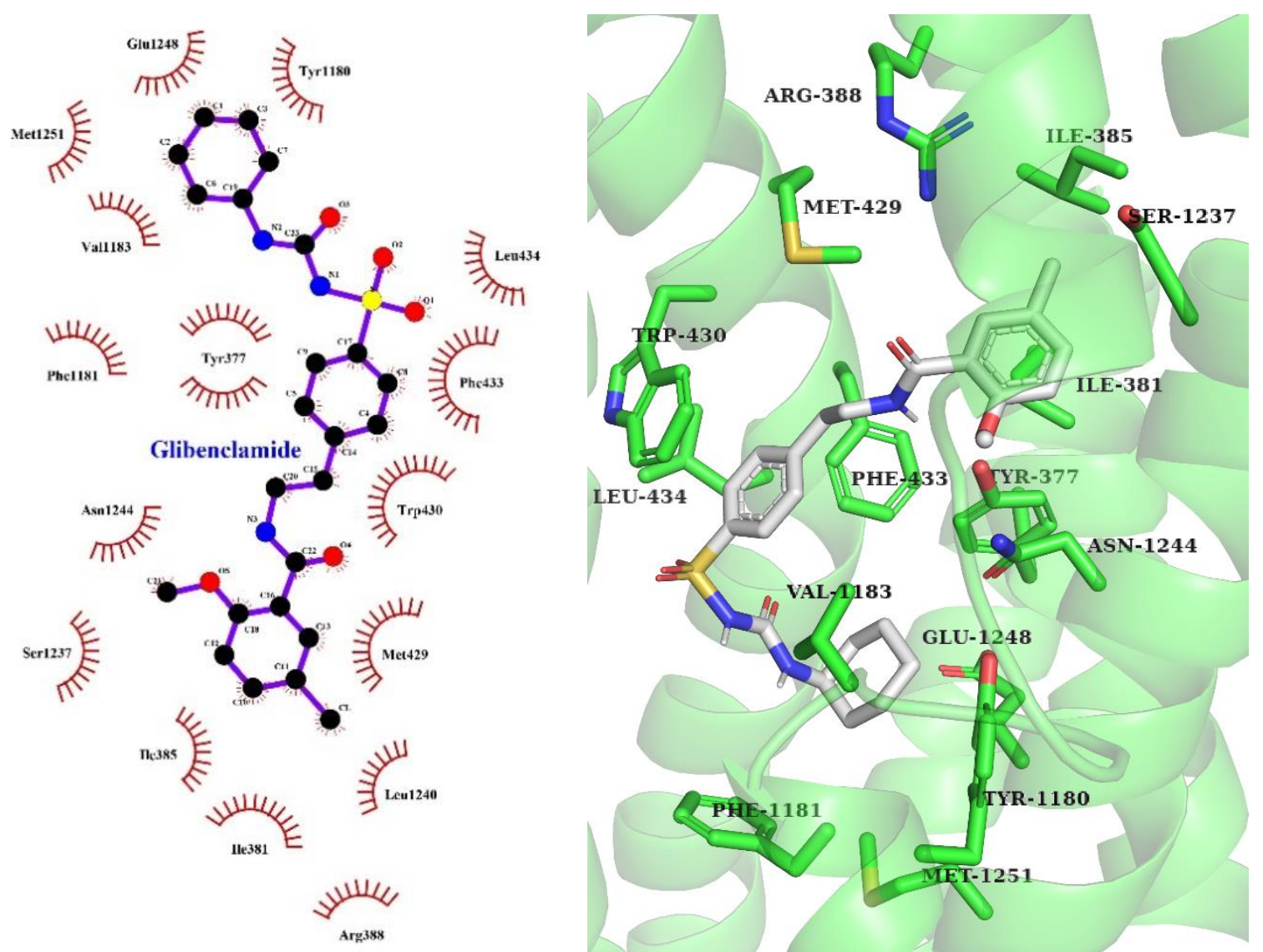

Figure 6. 2D and 3D illustrations of glibenclamide interactions with SUR1 active site.
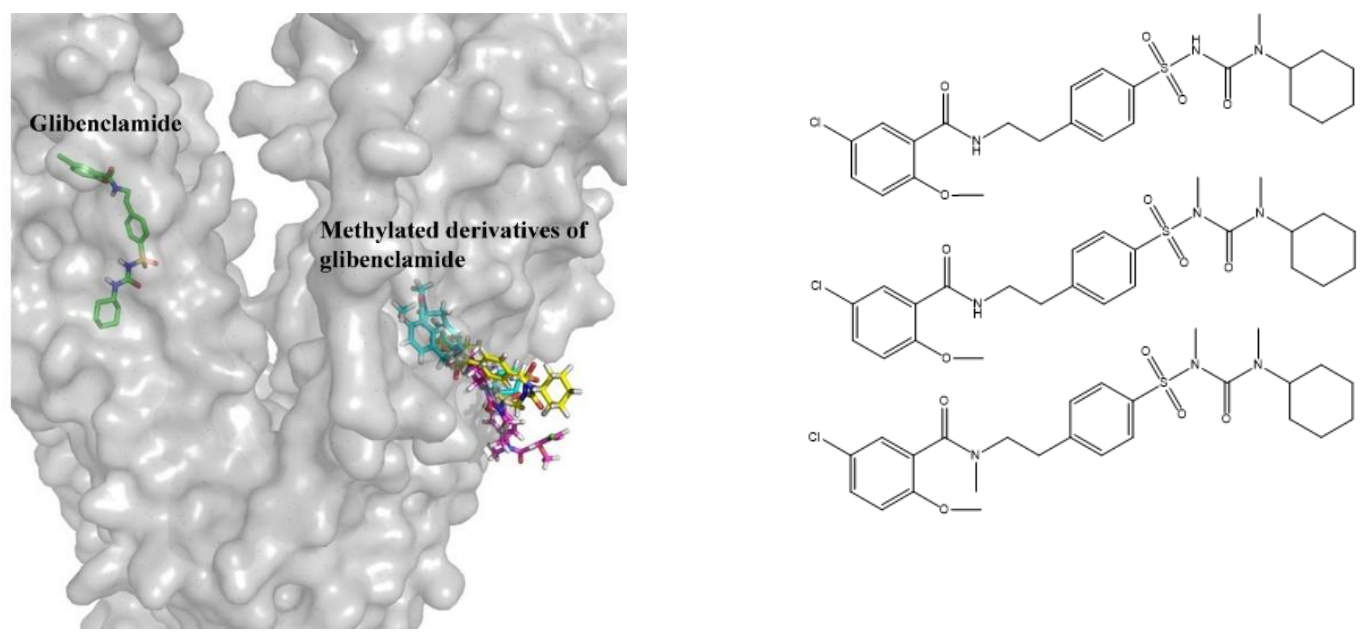

Figure 7. 3D illustration of the best-docked conformations of glibenclamide and its methylated derivatives in complex with SUR1. 
3.3. Docking of methylated derivatives of glibenclamide on SUR1.

As a weak acid, the major amount of glibenclamide $\left(\mathrm{pK}_{\mathrm{a}} 6.3\right)$ ionizes in $\mathrm{pH} 7.4$ while it exerts its inhibitory effect in its unionized form. In this study, we added one, two, and three methyl substituents to the nitrogen atoms of glibenclamide to improve its permeability. These three designed ligand molecules were docked on SUR1 to assess their possible docking energy and interactions with SUR1. Docking energies of methylated glibenclamide derivatives to SUR1 were $-9.1 \mathrm{kcal} / \mathrm{mol}$ for methyl glibenclamide, $-8.2 \mathrm{kcal} / \mathrm{mol}$ for dimethyl glibenclamide, and $-8 \mathrm{kcal} / \mathrm{mol}$ for trimethyl glibenclamide. It suggests that adding methyl substituents on nitrogen atoms decreases the potential inhibitory effect of glibenclamide against SUR1. Moreover, these derivatives showed to be bound in different regions than the glibenclamide binding region (Figure 7).

\subsection{Pharmacophore generation.}

A pharmacophore map based on glibenclamide-SUR1 interactions was generated using LigandScout [50]. Then, pharmacophore-based screening was done on the National Cancer Institution's Natural Product database by PubChem search engine. Nine compounds were obtained, and all inhibitors were docked over the SUR1 binding cavity (Table 1). Compounds $\mathrm{H}$ and I were chosen due to their structural similarity to glibenclamide, similar binding pocket, and lowest binding energies. Figure 8 shows the interactions made by compounds $\mathrm{H}$ and $\mathrm{I}$ against SUR1 and the residues involved.
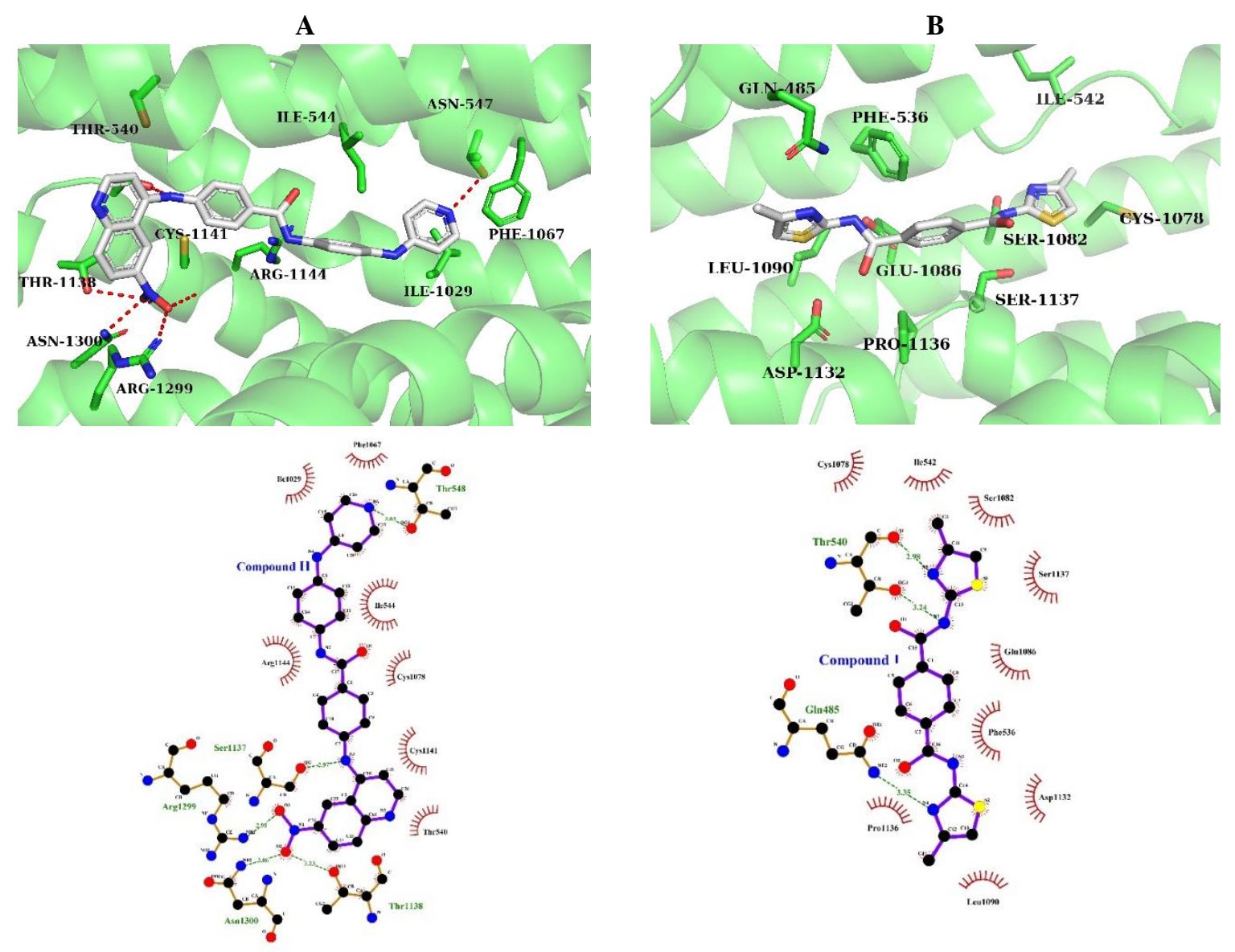

Figure 8. 2D and $3 \mathrm{D}$ views of the interactions made by compound $\mathrm{H}(\mathrm{A})$ and compound $\mathrm{I}(\mathrm{B})$. 
Compound H shows hydrogen bonding with residues Thr 548, Ser 1137, Arg 1299, Asn 1300, and Thr 1138, while hydrophobic is made by Phe 1067, Ile 1029, Ile 544, Arg 1144, Cys 1078, Cys 1141, Thr 540 (Figure 8 A). However, there are only two H-bonds in compound I binding formed by Thr 540 and Gln 485. Hydrophobic interactions in Cys 1078, Ile 542, Ser 1082, Ser 1137, Glu 1086, Phe 536, Asp 1132, Leu 1090, and Pro 1136 are involved in compound I and SUR1 (Figure 8 B).

To find more potential inhibitors, similarity screening was carried out in the PubChem database based on the $90 \%$ similarity to compounds $H$ and I. Fourteen compounds (1-14) were obtained and evaluated for their binding mode and interactions by docking to the SUR1 cavity (Table 2). We observed that all of the ligands exhibited a similar binding region to glibenclamide. However, except for compound 12 (CID-149074), all ligands have lower binding energy than glibenclamide. Compound 9 (CID-415537) and compound 12 (CID419074) were chosen for MD simulations due to their structural similarity to glibenclamide and desirable (lowest) docking energy. Figure 9 represents 2D and 3D conformations of compound 9 and 12-SUR1 complexes.
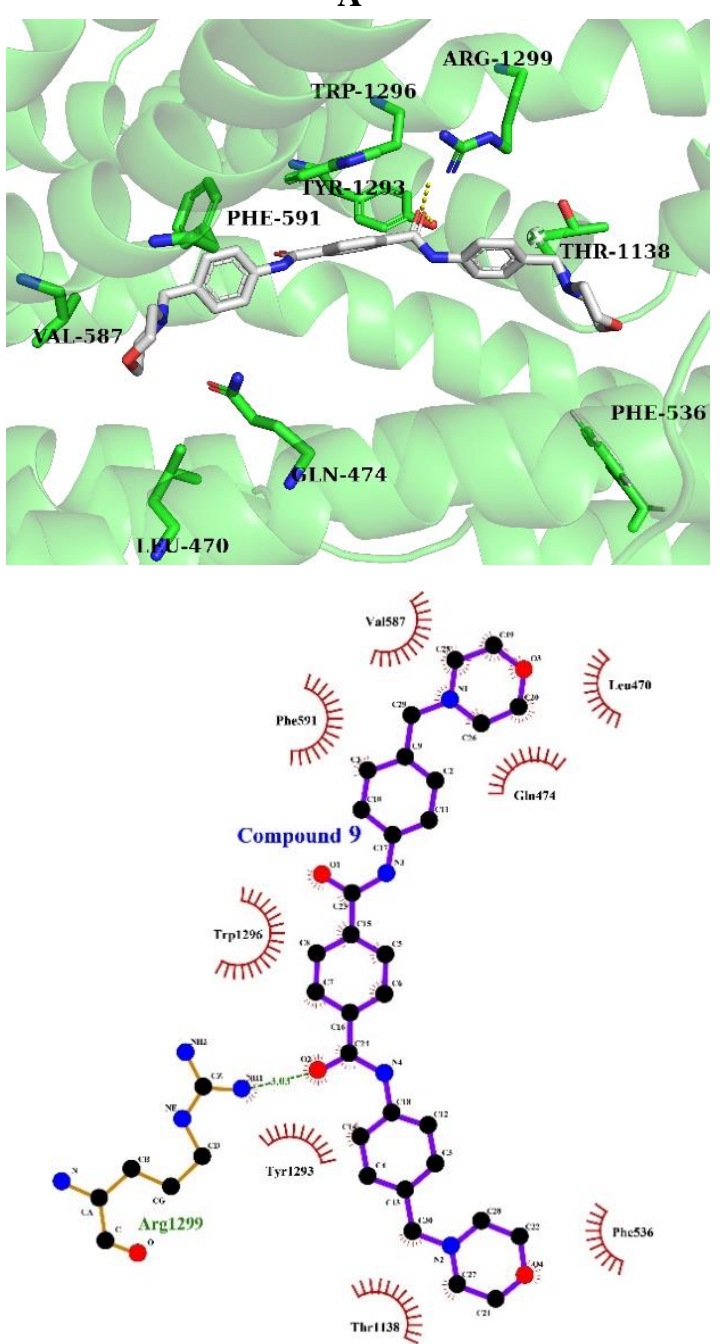
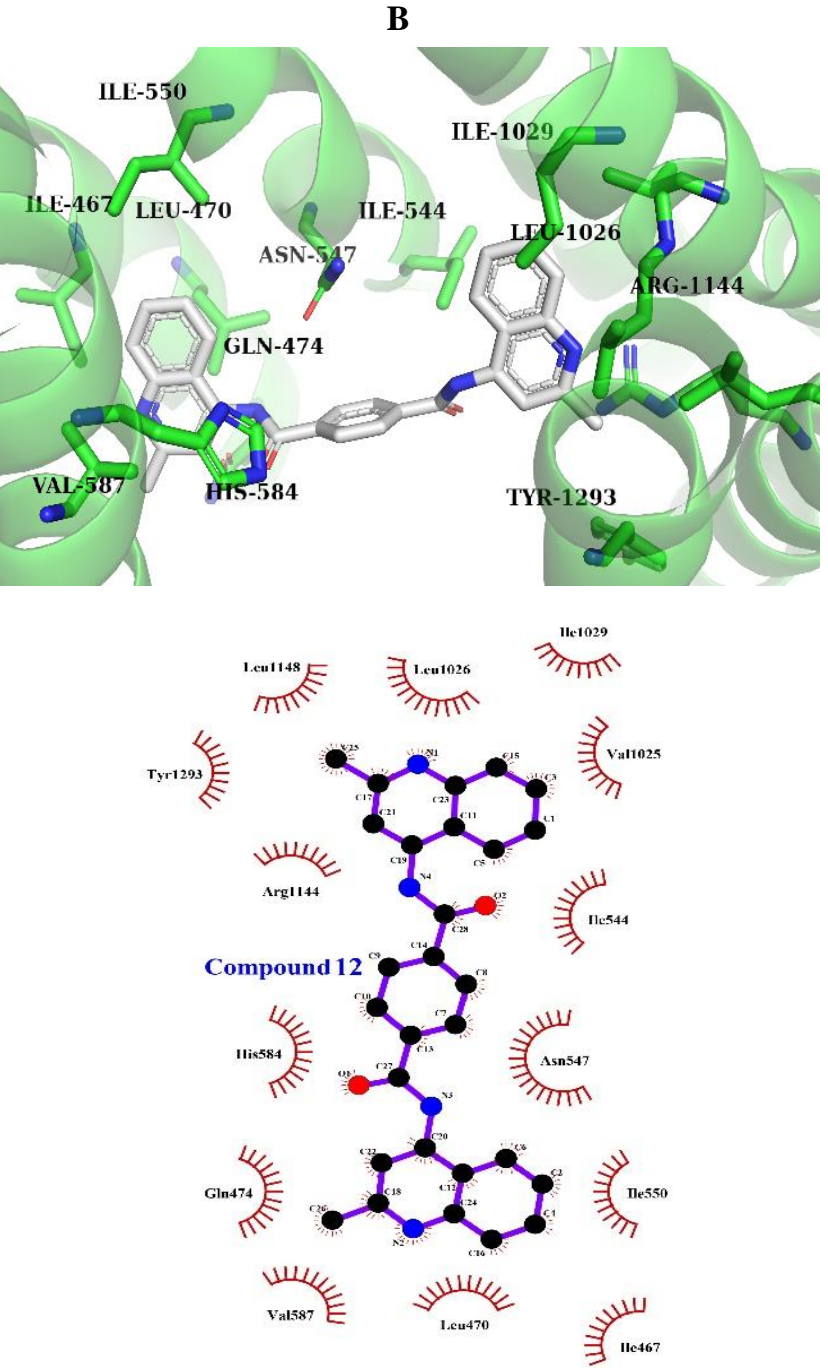

Figure 9. 3D and 2D representations of compound 9 (A) and compound 12 (B) generated by PyMol and LigPlot $^{+}$software, respectively. The ligands are shown in the sticks in 3D pictures, while surrounded residues are shown in green stick forms. 


\subsection{Molecular dynamic studies.}

Molecular dynamic simulations were performed on the lowest docked conformations of compounds 9, 12, and glibenclamide over SUR1 to evaluate their structural stability over 60 ns of simulation. The root means square deviation (RMSD) plots of compounds 9, 12, and glibenclamide indicate that these compounds tightly bind to the SUR1 binding pocket (Figure $10 \mathrm{~A})$.

It was expected that the protein bound to the ligand is more stable than the protein without the ligand. However, the RMSD plots of the protein backbone show that SUR1 is stable both without and in complex with the ligand. SUR1 is bound to glibenclamide, compounds 9 and 12, and their complex reaches the steady-state after $15 \mathrm{~ns}$ (Figure $10 \mathrm{~B}$ ). The free binding energy of ligands is much less than the overall energy of the whole protein (because of the large size of the protein). Therefore, ligand-protein interaction has no impact on the faster stability of the protein. To have a deep insight into the movements of active site residues in the presence of ligands, root means square fluctuation (RMSF) plots were calculated (Figure 11).
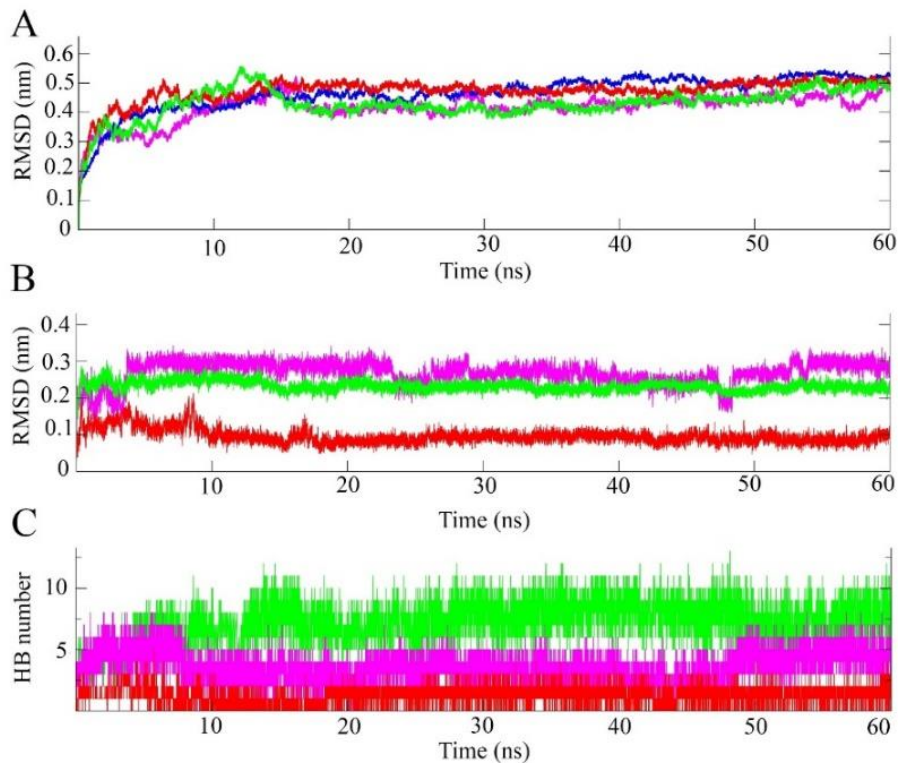

Figure 10. Molecular dynamic simulation graphs; (A) RMSD plot of protein in complex with glibenclamide (magenta), compound 9 (green), compound 12 (red), and protein without ligand (blue). (B) RMSD graph of glibenclamide, compound 9 and 12 in magenta, green and red colors, respectively. (C) several hydrogen bonds between ligands and protein active site residues. The color of ligands is the same as explained above.

It was observed that movements of active site residues in contact with ligands are lower than their movement without ligands. Also, the number of hydrogen bond between ligands and protein residues were studied (Figure $10 \mathrm{C}$ ). It is seen that compound 9 makes more hydrogen bonds than the other two compounds. In conclusion, compound 9 makes efficient interactions with the SUR1 binding region compared to glibenclamide and compound 12. Regarding both graphs, compound 9 is as stable as glibenclamide. So, compound 9 can be a potential candidate for mimicking glibenclamide interaction to inhibit the SUR1 receptor without hypoglycemic side effects.

\subsection{ADMET analysis.}

The prediction of drug-likeliness and toxicity of the candidates not only does ensures their safety but also affords the opportunity for further improvements in proposed compounds. 
The prediction analysis showed that both compounds had favorable properties according to various filters and no toxicity, as shown in Table 3.

Table 3. Predicted drug-likeness and toxicity of compounds 9 and 12.

\begin{tabular}{|c|c|c|c|c|c|c|c|}
\hline \multirow[b]{2}{*}{ Compound } & \multicolumn{5}{|c|}{ Drug-likeliness criteria } & \multirow{2}{*}{$\begin{array}{l}\text { Bioavailability } \\
\text { Score }^{f}\end{array}$} & \multirow{2}{*}{$\begin{array}{l}\text { Predicted Toxicity } \\
\text { Class }^{\mathrm{g}}\end{array}$} \\
\hline & Lipinski $^{\text {a }}$ & $\begin{array}{l}\text { Ghose } \\
\text { b }\end{array}$ & Veber $^{\mathrm{c}}$ & $\operatorname{Egan}^{\mathbf{d}}$ & Muegge $^{e}$ & & \\
\hline Compound 9 & Yes* & No & Yes & Yes & Yes & 0.55 & 4 \\
\hline Compound 12 & Yes & No & Yes & Yes & Yes & 0.55 & 4 \\
\hline \multicolumn{8}{|c|}{$\begin{array}{l}\text { a Lipinski's rule of } 5 \text { : MW }<500 \text { Dalton, } \log \mathrm{P}<5 \text {, hydrogen-bond donors }<5 \text {, hydrogen-bond acceptors }<10 \text {, } \\
\text { rotatable bonds }<10 \text {. }\end{array}$} \\
\hline \multicolumn{8}{|c|}{ b $160 \leq \mathrm{MW} \leq 480,-0.4 \leq \mathrm{WLOGP} \leq 5.6,40 \leq \mathrm{MR} \leq 130,20 \leq$ atoms $\leq 70$} \\
\hline \multicolumn{8}{|c|}{ c Rotatable bonds $\leq 10$, TPSA $\leq 140$} \\
\hline \multicolumn{8}{|c|}{$\mathrm{d}$ WLOGP $\leq 5.88$, TPSA $\leq 131.6$} \\
\hline \multirow{2}{*}{\multicolumn{8}{|c|}{$\begin{array}{l}\text { e } 200 \leq \mathrm{MW} \leq 600,-2 \leq \mathrm{XLOGP} \leq 5 \text {, TPSA } \leq 150 \text {, Num. rings } \leq 7 \text {, Num. carbon }>4 \text {, Num.heteroatoms }>1 \text {, } \\
\text { Num. rotatable bonds } \leq 15 \text {, H-bond acc } \leq 10 \text {, H-bond donor } \leq 5 \text {. }\end{array}$}} \\
\hline & & & & & & & \\
\hline \multicolumn{8}{|c|}{ f Probability of $F>10 \%$ in the rat. } \\
\hline \multicolumn{8}{|c|}{ g Carried out by ProTox-II. } \\
\hline
\end{tabular}

Glibenclamide is a weak acid; a significant amount of glibenclamide $\left(\mathrm{pK}_{\mathrm{a}} 6.3\right)$ ionizes at $\mathrm{pH} 7.4$. At the same time, it exerts its inhibitory effect in its unionized form $[58,59]$. On the other hand, the ischemic condition in which the cerebral $\mathrm{pH}$ is decreased [41] increases the lipid solubility of glibenclamide and facilitates the penetration through the blood-brain barrier BBB) [60]. Simard et al., in their studies on non-lethal and lethal rat models of ischemic stroke, estimated a time for delivery of glibenclamide. They observed that glibenclamide must be delivered up to 4-6 hours after non-lethal ischemic stroke and 6-10 hours after a lethal ischemic stroke to be beneficial [61-63]. Also, Weih and Favila, in independent studies, observed that the use of glibenclamide before ischemic stroke did not affect mortality, morbidity, and severity of stroke [64-65]. All these observations confirmed sulfonylurea drugs application in the CIA, especially glibenclamide, in a few hours reduces $\mathrm{CNS} \mathrm{pH}, \mathrm{BBB}$ disintegration, and upregulation of SUR1.

The SUR1 protein is a calcium and ATP-sensitive nonselective cation channel that is upregulated in ischemic conditions and is responsible for brain edema and cell death [11]. SUR1-Trpm 4 channels are inhibited by glibenclamide and tolbutamide, two sulfonylurea drugs [27]. These drugs can reduce mortality and edema, and decrease infarct volume and increase cerebral blood flow in stroke conditions through binding to the SUR1 subunit [58], but hypoglycemic side effects of sulfonylurea prevent their general use in daily clinic safely.

SUR1 ligands (SUR1 openers such as SR47063, P1075, diazoxide, and SUR1 blockers such as glibenclamide, tolbutamide, meglitinide) have been reported to interact with Pglycoproteins (P-gp) but with less affinity [66].

Since there is no crystallized 3D structure for brain SUR1, we generated its 3D structure by homology modeling. The structural superposition revealed that there are close structural similarities between the binding site of SUR1 and P-gp. This comparison showed that Ser 1237 in SUR1 is equivalent to Ser 931 in P-gp, Thr 1285, and Met 1289 in SUR1 equivalent to Ser 979 and Phe 983 were associated with binding of different ligands. Evaluations of the SUR 1 proposed model showed that the glibenclamide binding site based on the articles mentioned above is associated with Ala 927 in P-gp equivalent to Ser 1237 in SUR1. This implies a structural similarity between SUR1 and P-gp binding pockets. Ser 1237 in the SUR1 sequence was identified as an equivalent residue to Ser 931 in P-gp which both are associated with 
glibenclamide binding [67]. Therefore, we used the 3D structure of P-gp for homology modeling, and Ser 1237 was considered for determining the approximate SUR1 binding pocket. Moreover, their findings are consistent with our results. Glibenclamide shows a better affinity to SUR1 than P-gp due to its lower binding energy $(-10.7$ and $-9.3 \mathrm{kcal} / \mathrm{mol}$ in complex with SUR1 and P-gp, respectively (Figures 5 and 6).
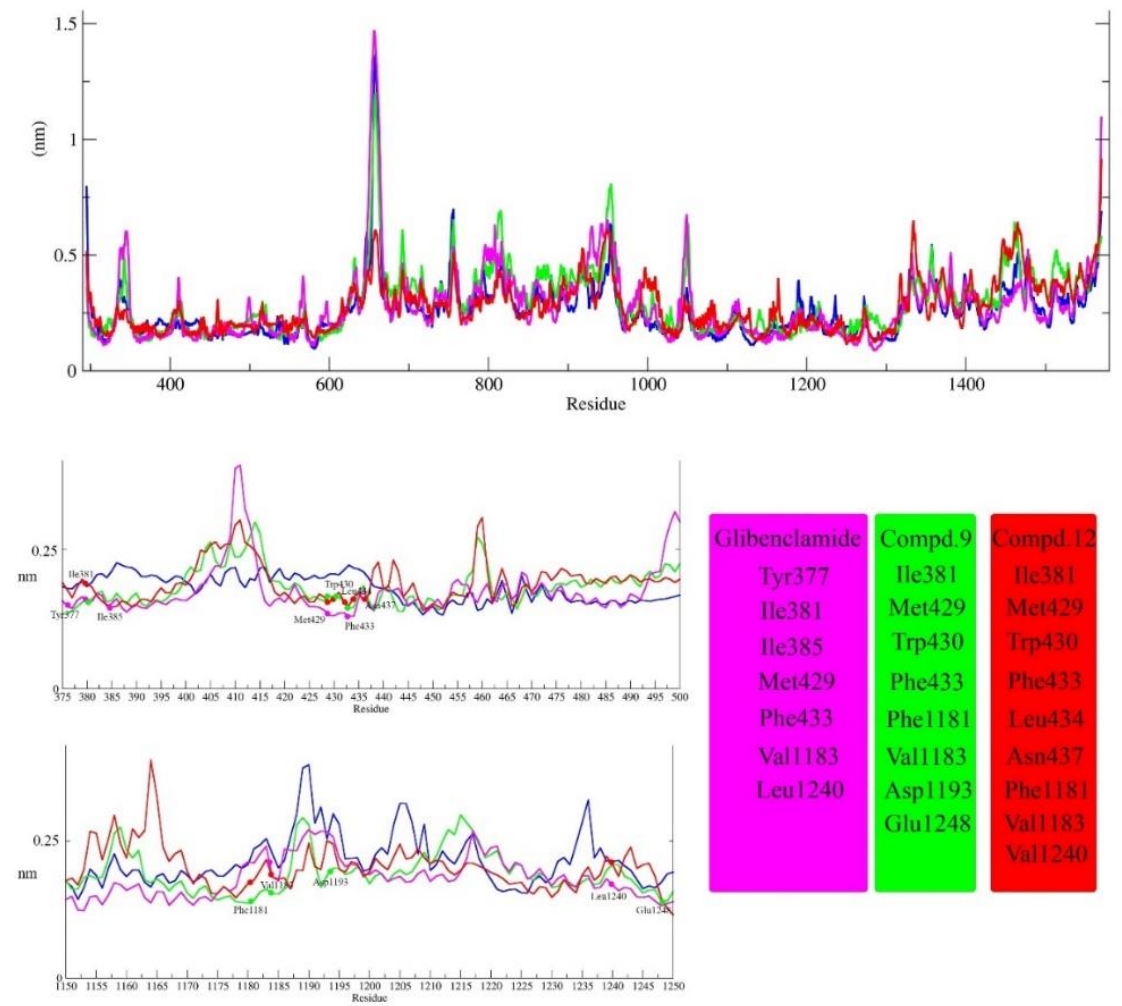

Figure 11. Root mean square fluctuation (RMSF) graphs; the above picture shows amino acids (range of 3501585) movements in contact with glibenclamide (magenta), compound 9 (green), compound 12 (red), and protein without ligand (blue). The other two graphs indicate the fluctuation of amino acids in ranges of 375-500 and 11501250 to focus on essential amino acids inside the active site.

\section{Conclusions}

In this study, we used the structural features of glibenclamide to find new potential inhibitors of SUR1 without potential hypoglycemic side effects of sulfonylurea drugs through docking study.

Therefore, we added one, two, and three methyl substituents to the nitrogen atoms of glibenclamide to increase its lipophilicity and improve its permeability and possible inhibitory potential. These three designed molecules were docked on SUR1 to assess their possible docking energy and interactions with SUR1. However, results show that lipophilicity is not essential for binding ligands to the SUR1 active site. We observed that increasing the lipophilic properties by adding methyl groups decreases the inhibitor affinity and different binding regions than glibenclamide (Figure 7). It can be realized that there is not enough space in the SUR1 binding cavity for enlarged nitrogen groups to accommodate.

In the next step, several filters that are believed to be necessary for BBB penetration were applied for screening the NCI database. We choose compounds $\mathrm{H}$ and I due to structural similarity to glibenclamide and appropriate binding energy after virtual screening and docking simulations. Subsequent similarity screening was carried out based on a $90 \%$ similarity with these two compounds using the PubChem structure search engine. In other words, this 
screening was done to enlarge the potential inhibitors based on the maximum similarity to glibenclamide and the ability for BBB penetration. Among fourteen compounds retrieved from the NCI database, compounds 9 and 12 were chosen for the next study step due to their higher binding energy and appropriate binding pattern against SUR1 (Table 2).

Molecular dynamic simulation results confirmed that these compounds tightly bind to the SUR1 binding pocket (Figure 10 A). SUR1 is bound to glibenclamide, compounds 9 and 12 , and their complex reaches the steady-state after $15 \mathrm{~ns}$ of simulation (Figure $10 \mathrm{~B}$ ). Moreover, SUR1 is stable both without and in complex with the ligand, and binding to ligands has no impact on the faster stability of the protein. It was observed that movements of active site residues in contact with ligands are lower than their movement without ligands (Figure 11).

All these reports and observations suggest that the most similar compound in structure to glibenclamide also improved the ability of $\mathrm{BBB}$ penetration in neutral $\mathrm{pH}$ and relatively normal conditions that will be superior to glibenclamide in ischemic strokes and may prevent the expansion of ischemic lesions, morbidity, and mortality, consistent with "time in brain" principle. In conclusion, it seems that compound 9 has the most similar structure to glibenclamide and can penetrate through the $\mathrm{BBB}$ and enter the brain at neutral $\mathrm{pH}$ and a relatively normal situation. Therefore, glibenclamide may excel in ischemic strokes and prevent the expansion of ischemic lesions, morbidity, and mortality. It might be expected that compound 9 decreases the ischemic consequences through disrupting SUR1 contacts forming SUR1-Trpm4. Failure in developing ion channels results in a decrease in sodium ions input and prevents brain swelling. Although further experiments are needed to approve these data however we believe that our computer-aided simulations would help lead to compound consideration.

\section{Funding}

This research was funded by the Tehran University of Medical Sciences and Health Services.

\section{Conflicts of Interest}

The authors declare no conflict of interest. The funders had no role in the study's design, in the collection, analyses, or interpretation of data, in the writing of the manuscript, or in the decision to publish the results.

\section{References}

1. Krishnamurthi, R.V.; deVeber, G.; Feigin, V.L.; Barker-Collo, S.; Fullerton, H.; Mackay, M.T.; O’Callahan, F.; Lindsay, M.P.; Kolk, A.; Lo, W.; Shah, P.; Linds, A.; Jones, K.; Parmar, P.; Taylor, S.; Norrving, B.; Mensah, G.A.; Moran, A.E.; Naghavi, M.; Forouzanfar, M.H.; Nguyen, G.; Johnson, C.O.; Vos, T.; Murray, C.J.L.; Roth, G.A. Stroke Prevalence, Mortality and Disability-Adjusted Life Years in Children and Youth Aged 0-19 Years: Data from the Global and Regional Burden of Stroke 2013. Neuroepidemiology 2015, 45, 177-189, https://doi.org/10.1159/000441087.

2. Kuriakose, D.; Xiao, Z. Pathophysiology and treatment of stroke: Present status and future perspectives. Int. J. Mol. Sci. 2020, 21, https://doi.org/10.3390/ijms21207609.

3. Girnar, G.A.; Mahajan, H.S. Cerebral ischemic stroke and different approaches for treatment of stroke. Future J. Pharm. Sci. 2021, 7, 1-10, https://doi.org/10.1186/s43094-021-00289-1.

4. Fisher, M. Stroke: Clinical manifestations and pathogenesis. Elsevier Health Sciences, 2009.

5. Harukuni, I.; Bhardwaj, A. Mechanisms of brain injury after global cerebral ischemia. Neurol. Clin. 2006, 24, 1-21, https://doi.org/10.1016/j.ncl.2005.10.004.

6. O'Brien, M.D. Ischemic cerebral edema. A review. Stroke 1979, 10, 623-8. https://doi.org/10.1161/01.str.10.6.623. 
7. Stokum, J.A.; Gerzanich, V.; Simard, J.M. Molecular pathophysiology of cerebral edema. J. Cereb. Blood Flow Metab. 2016, 36, 513-38, https://doi.org/10.1177/0271678X15617172.

8. Song, M.; Yu, S.P. Ionic regulation of cell volume changes and cell death after ischemic stroke. Transl. Stroke Res. 2014, 5, 17-27, https://doi.org/10.1007/s12975-013-0314-x.

9. Fan, J.L.; Brassard, P.; Rickards, C.A.; Nogueira, R.C.; Nasr, N.; McBryde, F.D.; Fisher, J.P.; Tzeng, Y.C. Integrative cerebral blood flow regulation in ischemic stroke. J. Cereb. Blood Flow Metab. 2021, https://doi.org/10.1177/0271678X211032029.

10. Pluta, R.; Januszewski, S.; Czuczwar, S.J. Neuroinflammation in post-ischemic neurodegeneration of the brain: Friend, foe, or both? Int. J. Mol. Sci. 2021, 22, https://doi.org/10.3390/ijms22094405.

11. Mehta, R.I.; Ivanova, S.; Tosun, C.; Castellani, R.J.; Gerzanich, V.; Simard, J.M. Sulfonylurea receptor 1 expression in human cerebral infarcts. J. Neuropathol. Exp. Neurol. 2013, 72, 871-83, https://doi.org/10.1097/NEN.0b013e3182a32e40.

12. Alquisiras-Burgos, I.; Franco-Perez, J.; Rubio-Osornio, M.; Aguilera, P. The short form of the SUR1 and its functional implications in the damaged brain. Neural. Regen. Res. 2022, 17, 488-496, https://doi.org/10.4103/1673-5374.320967.

13. Woo, S.K.; Kwon, M.S.; Ivanov, A.; Gerzanich, V.; Simard, J.M. The sulfonylurea receptor 1 (Sur1)-transient receptor potential melastatin 4 (Trpm4) channel. J. Biol. Chem. 2013, 288, 3655-67, https://doi.org/10.1074/jbc.M112.428219.

14. Simard, J.M.; Woo, S.K.; Schwartzbauer, G.T.; Gerzanich, V. Sulfonylurea receptor 1 in central nervous system injury: a focused review. J. Cereb. Blood Flow Metab. 2012, 32, 1699-717, https://doi.org/10.1038/jcbfm.2012.91.

15. Mehta, R.I.; Tosun, C.; Ivanova, S.; Tsymbalyuk, N.; Famakin, B.M.; Kwon, M.S.; Castellani, R.J.; Gerzanich, V.; Simard, J.M. Sur1-Trpm4 cation channel expression in human cerebral infarcts. J. Neuropathol. Exp. Neurol. 2015, 74, 835-49, https://doi.org/10.1097/NEN.0000000000000223.

16. Otsu, Y.; Namekawa, M.; Toriyabe, M.; Ninomiya, I.; Hatakeyama, M.; Uemura, M.; Onodera, O.; Shimohata, T.; Kanazawa, M. Strategies to prevent hemorrhagic transformation after reperfusion therapies for acute ischemic stroke: A literature review. J. Neurol. Sci. 2020, 419, https://doi.org/10.1016/j.jns.2020.117217.

17. Tata, S.; Zusman, B.E.; Kochanek, P.M.; Gerzanich, V.; Kwon, M.S.; Woo, S.K.; Clark, R.S.B.; JaneskoFeldman, K.; Vagni, V.A.; Simard, J.M.; Jha, R.M. Abcc8 (Sulfonylurea Receptor-1) Impact on Brain Atrophy after Traumatic Brain Injury Varies by Sex. Journal of Neurotrauma 2021, 38, 2473-2485, https://doi.org/10.1089/neu.2021.0105.

18. Simard, J.M.; Woo, S.K.; Gerzanich, V. Transient receptor potential melastatin 4 and cell death. Pflugers Arch. 2012, 464, 573-82, https://doi.org/10.1007/s00424-012-1166-z.

19. Arundine, M.; Tymianski, M. Molecular mechanisms of calcium-dependent neurodegeneration in excitotoxicity. Cell Calcium 2003, 34, 325-37, https://doi.org/10.1016/s0143-4160(03)00141-6.

20. Roeper, B.L.J. Molecular physiology of neuronal K-ATP channels. Mol. Membr. Biol. 2009, 18, 117-127, https://doi.org/10.1080/09687680110047373.

21. Maqoud, F.; Scala, R.; Hoxha, M.; Zappacosta, B.; Tricarico, D. ATP-sensitive potassium channel subunits in the neuroinflammation: novel drug targets in neurodegenerative disorders. CNS Neurol. Disord. Drug Targets 2021, https://doi.org/10.2174/1871527320666210119095626.

22. Tosun, C.; Kurland, D.B.; Mehta, R.; Castellani, R.J.; deJong, J.L.; Kwon, M.S.; Woo, S.K.; Gerzanich, V.; Simard, J.M. Inhibition of the Sur1-Trpm4 channel reduces neuroinflammation and cognitive impairment in subarachnoid hemorrhage. Stroke 2013, 44, 3522-8, https://doi.org/10.1161/STROKEAHA.113.002904.

23. Woo, S.K.; Tsymbalyuk, N.; Tsymbalyuk, O.; Ivanova, S.; Gerzanich, V.; Simard, J.M. SUR1-TRPM4 channels, not KATP, mediate brain swelling following cerebral ischemia. Neurosci. Lett. 2020, 718, https://doi.org/10.1016/j.neulet.2019.134729.

24. Dundar, T.T.; Abdallah, A.; Yurtsever, I.; Guler, E.M.; Ozer, O.F.; Uysal, O. Serum SUR1 and TRPM4 in patients with subarachnoid hemorrhage. Neurosurg. Rev. 2020, 43, 1595-1603, https://doi.org/10.1007/s10143-019-01200-6.

25. Huang, Q.; Wang, X.; Lin, X.; Zhang, J.; You, X.; Shao, A. The role of transient receptor potential channels in blood-brain barrier dysfunction after ischemic stroke. Biomed. Pharmacother. 2020, 131, https://doi.org/10.1016/j.biopha.2020.110647.

26. Pergakis, M.; Badjatia, N.; Simard, J. M. An update on the pharmacological management and prevention of cerebral edema: current therapeutic strategies. Expert Opin. Pharmacother. 2021, 22, 1025-1037, https://doi.org/10.1080/14656566.2021.1876663.

27. Chen, M.; Dong, Y.; Simard, J.M. Functional coupling between sulfonylurea receptor type 1 and a nonselective cation channel in reactive astrocytes from adult rat brain. J. Neurosci. 2003, 23, 8568-8577, https://doi.org/10.1523/JNEUROSCI.23-24-08568.2003.

28. Simard, J.M.; Woo, S.K.; Bhatta, S.; Gerzanich, V. Drugs acting on SUR1 to treat CNS ischemia and trauma. Curr. Opin. Pharmacol. 2008, 8, 42-9, https://doi.org/10.1016/j.coph.2007.10.004.

29. Berdugo, M.; Delaunay, K.; Naud, M.-C.; Guegan, J.; Moulin, A.; Savoldelli, M.; Picard, E.; Radet, L.; Jonet, L.; Djerada, Z.; Gozalo, C.; Daruich, A.; Beltrand, J.; Jeanny, J.-C.; Kermorvant-Duchemin, E.; Crisanti, P.; 
Polak, M.; Behar-Cohen, F. The antidiabetic drug glibenclamide exerts direct retinal neuroprotection. Translational Research 2021, 229, 83-99, https://doi.org/10.1016/j.trsl.2020.10.003.

30. Wang, X.; Chang, Y.; He, Y.; Lyu, C.; Li, H.; Zhu, J.; Liu, K.; Hu, Y.; Huang, K.; Pan, S. Glimepiride and glibenclamide have comparable efficacy in treating acute ischemic stroke in mice. Neuropharmacology 2020, 162, https://doi.org/10.1016/j.neuropharm.2019.107845.

31. Jha, R.M.; Mondello, S.; Bramlett, H.M.; Dixon, C.E.; Shear, D.A.; Dietrich, W.D.; Wang, K.K.W.; Yang, Z.; Hayes, R.L.; Poloyac, S.M.; Empey, P.E.; Lafrenaye, A.D.; Yan, H.Q.; Carlson, S.W.; Povlishock, J.T.; Gilsdorf, J.S.; Kochanek, P.M. Glibenclamide Treatment in Traumatic Brain Injury: Operation Brain Trauma Therapy. Journal of Neurotrauma 2020, 38, 628-645, https://doi.org/10.1089/neu.2020.7421.

32. Wen, L.; Huang, B.; Tu, R.; Wan, K.; Zhang, H.; Zhang, X. Effectiveness and safety of glibenclamide for stroke: protocol for a systematic review and meta-analysis. BMJ Open 2021, 11, https://doi.org/10.1136/bmjopen-2020-043585.

33. Thompson, E.M.; Pishko, G.L.; Muldoon, L.L.; Neuwelt, E.A. Inhibition of SUR1 decreases the vascular permeability of cerebral metastases. Neoplasia 2013, 15, 535-43, https://doi.org/10.1593/neo.13164.

34. Zubov, A.; Muruzheva, Z.; Tikhomirova, M.; Karpenko, M. Glibenclamide as a neuroprotective antidementia drug. Arch. Physiol. Biochem. 2020, 1-4, https://doi.org/10.1080/13813455.2020.1789170.

35. Robert, S.M.; Reeves, B.C.; Alper, S.L.; Zhang, J.; Kahle, K.T. New drugs on the horizon for cerebral edema: what's in the clinical development pipeline? Expert Opin. Investig. Drugs 2020, 29, 1099-1105, https://doi.org/10.1080/13543784.2020.1813715.

36. Huang, K.; Ji, Z.; Wu, Y.; Huang, Y.; Li, G.; Zhou, S.; Yang, Z.; Huang, W.; Yang, G.; Weng, G.; Chen, P.; Pan, S. Safety and efficacy of glibenclamide combined with rtPA in acute cerebral ischemia with occlusion/stenosis of anterior circulation (SE-GRACE): study protocol for a randomized controlled trial. BMC Neurology 2020, 20, https://doi.org/10.1186/s12883-020-01823-z.

37. Igarashi, T.; Sastre, C.; Wolcott, Z.; Kimberly, W.T. Continuous glibenclamide prevents hemorrhagic transformation in a rodent model of severe ischemia-reperfusion. J. Stroke Cerebrovasc. Dis. 2021, 30, https://doi.org/10.1016/j.jstrokecerebrovasdis.2020.105595.

38. Simard, J.M.; Sheth, K.N.; Kimberly, W.T.; Stern, B.J.; del Zoppo, G.J.; Jacobson, S.; Gerzanich, V. Glibenclamide in cerebral ischemia and stroke. Neurocrit. Care 2014, 20, 319-33, https://doi.org/10.1007/s12028-013-9923-1.

39. Tomiyama, Y.; Brian, J.E.J.; Todd, M.M. Cerebral blood flow during hemodilution and hypoxia in rats : role of ATP-sensitive potassium channels. Stroke 1999, 30, 1942-7-1947-8, https://doi.org/10.1161/01.str.30.9.1942.

40. Griepp, D.W.; Lee, J.; Moawad, C.M.; Davati, C.; Runnels, J.; Fiani, B. BIIB093 (intravenous glibenclamide) for the prevention of severe cerebral edema. Surg. Neurol. Int. 2021, 12, https://doi.org/10.25259/SNI_933_2020.

41. Nedergaard, M.; Kraig, R. P.; Tanabe, J.; Pulsinelli, W.A. Dynamics of interstitial and intracellular pH in evolving brain infarct. Am. J. Physiol. 1991, 260, R581-8, https://doi.org/10.1152/ajpregu.1991.260.3.R581.

42. Upadhyay, R.K. Drug delivery systems, CNS protection, and the blood brain barrier. Biomed. Res. Int. 2014, 2014, https://doi.org/10.1155/2014/869269.

43. Raghunand, N.; Gillies, R.J. pH and drug resistance in tumors. Drug Resist. Updat. 2000, 3, 39-47, https://doi.org/10.1054/drup.2000.0119.

44. Kamp, F.; Kizilbash, N.; Corkey, B.E.; Berggren, P.O.; Hamilton, J.A. Sulfonylureas rapidly cross phospholipid bilayer membranes by a free-diffusion mechanism. Diabetes 2003, 52, 2526-31, https://doi.org/10.2337/diabetes.52.10.2526.

45. Sternberg, M.J. Protein structure prediction: A practical approach: a practical approach. Oxford University Press, USA, 1996.

46. MarvinSketch (version 17.8.0), calculation module developed by ChemAxon, http://www.chemaxon.com/products/marvin/marvinsketch/, 2012.

47. Trott, O.; Olson, A.J. AutoDock Vina: improving the speed and accuracy of docking with a new scoring function, efficient optimization, and multithreading. J. Comput. Chem. 2010, 31, 455-61, https://doi.org/10.1002/jcc.21334.

48. DeLano, W.L. The PyMOL molecular graphics system. 2002; http://pymol.org/.

49. Wallace, A.C.; Laskowski, R.A.; Thornton, J.M. LIGPLOT: a program to generate schematic diagrams of protein-ligand interactions. Protein Eng. 1995, 8, 127-34, https://doi.org/10.1093/protein/8.2.127.

50. Wolber, G.; Langer, T. LigandScout: 3-D pharmacophores derived from protein-bound ligands and their use as virtual screening filters. J. Chem. Inf. Model. 2005, 45, 160-169, https://doi.org/10.1021/ci049885e.

51. van de Waterbeemd, H.; Camenisch, G.; Folkers, G.; Chretien, J.R.; Raevsky, O.A. Estimation of blood-brain barrier crossing of drugs using molecular size and shape, and H-bonding descriptors. J. Drug Target. 1998, 6, 151-165, https://doi.org/10.3109/10611869808997889.

52. Pronk, S.; Páll, S.; Schulz, R.; Larsson, P.; Bjelkmar, P.; Apostolov, R.; Shirts, M.R.; Smith, J.C.; Kasson, P.M.; van der Spoel, D.; Hess, B.; Lindahl, E. GROMACS 4.5: a high-throughput and highly parallel open source molecular simulation toolkit. Bioinformatics 2013, 29, 845-854, https://doi.org/10.1093/bioinformatics/btt055. 
53. Olsson, M.H.; Sondergaard, C.R.; Rostkowski, M.; Jensen, J.H. PROPKA3: Consistent treatment of internal and surface residues in empirical pka predictions. J. Chem. Theory Comput. 2011, 7, 525-37, https://doi.org/10.1021/ct100578z.

54. SchuĖttelkopf, A.W.; Van Aalten, D.M. PRODRG: a tool for high-throughput crystallography of proteinligand complexes. Acta Crystallogr., Sect. D: Biol. Crystallogr. 2004, 60, 1355-1363, https://doi.org/10.1107/S0907444904011679. .

55. Bagherzadeh, K.; Shirgahi Talari, F.; Sharifi, A.; Ganjali, M.R.; Saboury, A.A.; Amanlou, M. A new insight into mushroom tyrosinase inhibitors: docking, pharmacophore-based virtual screening, and molecular modeling studies. J. Biomol. Struct. Dyn. 2015, 33, 487-501, https://doi.org/10.1080/07391102.2014.893203.

56. Daina, A.; Michielin, O.; Zoete, V. SwissADME: a free web tool to evaluate pharmacokinetics, drug-likeness and medicinal chemistry friendliness of small molecules. Sci. Rep. 2017, 7, https://doi.org/10.1038/srep42717.

57. Banerjee, P.; Eckert, A.O.; Schrey, A.K.; Preissner, R. ProTox-II: a webserver for the prediction of toxicity of chemicals. Nucleic Acids Res. 2018, 46, W257-W263, https://doi.org/10.1093/nar/gky318.

58. Findlay, I. Effects of $\mathrm{pH}$ upon the inhibition by sulphonylurea drugs of ATP-sensitive K+ channels in cardiac muscle. J. Pharmacol. Exp. Ther. 1992, 262, 71-79.

59. Zünkler, B.; Trube, G.; Panten, U. How do sulfonylureas approach their receptor in the B-cell plasma membrane? Naunyn Schmiedebergs Arch. Pharmacol. 1989, 340, 328-332, https://doi.org/10.1007/BF00168518.

60. Simard, J.M.; Chen, M.; Tarasov, K.V.; Bhatta, S.; Ivanova, S.; Melnitchenko, L.; Tsymbalyuk, N.; West, G.A.; Gerzanich, V. Newly expressed SUR1-regulated NCCa-ATP channel mediates cerebral edema after ischemic stroke. Nat. Med. 2006, 12, 433-440, https://doi.org/10.1038/nm1390.

61. Simard, J.M.; Yurovsky, V.; Tsymbalyuk, N.; Melnichenko, L.; Ivanova, S.; Gerzanich, V. Protective effect of delayed treatment with low-dose glibenclamide in three models of ischemic stroke. Stroke 2009, 40, 6049, https://doi.org/10.1161/STROKEAHA.108.522409.

62. Simard, J.M.; Tsymbalyuk, N.; Tsymbalyuk, O.; Ivanova, S.; Yurovsky, V.; Gerzanich, V. Glibenclamide is superior to decompressive craniectomy in a rat model of malignant stroke. Stroke 2010, 41, 531-7, https://doi.org/10.1161/STROKEAHA.109.572644.

63. Simard, J.M.; Woo, S.K.; Tsymbalyuk, N.; Voloshyn, O.; Yurovsky, V.; Ivanova, S.; Lee, R.; Gerzanich, V. Glibenclamide-10-h treatment window in a clinically relevant model of stroke. Transl. Stroke Res. 2012, 3, 286-95, https://doi.org/10.1007/s12975-012-0149-x.

64. Favilla, C.G.; Mullen, M.T.; Ali, M.; Higgins, P.; Kasner, S.E. Sulfonylurea use before stroke does not influence outcome. Stroke 2011, 42, 710-5, https://doi.org/10.1161/STROKEAHA.110.599274.

65. Weih, M.; Amberger, N.; Wegener, S.; Dirnagl, U.; Reuter, T.; Einhaupl, K. Sulfonylurea drugs do not influence initial stroke severity and in-hospital outcome in stroke patients with diabetes. Stroke 2001, 32, 2029-32, https://doi.org/10.1161/str.32.9.2029.

66. Golstein, P.E.; Boom, A.; van Geffel, J.; Jacobs, P.; Masereel, B.; Beauwens, R. P-glycoprotein inhibition by glibenclamide and related compounds. Pflugers Arch. 1999, 437, 652-60, https://doi.org/10.1007/s004240050829.

67. Bessadok, A.; Garcia, E.; Jacquet, H.; Martin, S.; Garrigues, A.; Loiseau, N.; André, F.; Orlowski, S.; Vivaudou, M. Recognition of sulfonylurea receptor (abcc8/9) ligands by the multidrug resistance transporter p-glycoprotein (abcb1) functional similarities based on common structural features between two multispecific abc proteins. J. Biol. Chem. 2011, 286, 3552-3569, https://doi.org/10.1074/jbc.M110.155200. 